\title{
Correlation of ultrasound placental diameter \& thickness with gestational age
}

\author{
Ngozi R. Njeze', Joseph O. Ogbochukwu², Josephat M. Chinawa
}

\begin{abstract}
Background \& Objectives: Estimation of fetal maturity is common in obstetric practice especially when the women do not keep accurate menstrual records. An accurate establishment of expected date of delivery is fundamental to the management of both high risk and normal pregnancies. The objective of this study was to determine the placental diameter (PD), placental thickness (PT) and to establish a correlation between PD, PT and gestational age.

Methods: This is an observational cross-sectional study that examines by means of ultrasonography the correlation between placental diameter and thickness with gestational age in Enugu, South East, Nigeria.

Results: A total of 400 healthy subjects were recruited in $3^{\text {rd }}$ trimester of pregnancy having fulfilled the inclusion criteria. PD and PT in this study did not correlate with parity. There is a linear increase of gestational age and placental thickness and diameter. These increases heighten between $38^{\text {th }}$ week gestation and 40 weeks' gestation. $205.0 \pm 1.4,43.00 \pm 0.0$ to $215.0 \pm 1.4,46.00 \pm 2.8$ respectively.

Conclusion: Placental thickness and Placental diameter can be used to predict gestational age. It is therefore advised to use PT \& PD in ultrasound obstetric assessment especially when Last menstrual period (LMP) is not clear.
\end{abstract}

KEYWORDS: Placenta, Ultrasonography, Gestational age, Enugu-Nigeria.

How to cite this:

doi: https://doi.org/10.12669/pjms.36.5.1938

Njeze NR, Ogbochukwu JO, Chinawa JM. Correlation of ultrasound placental diameter \& thickness with gestational age. Pak J Med Sci. 2020;36(5):1058-1062. doi: https://doi.org/10.12669/pjms.36.5.1938

This is an Open Access article distributed under the terms of the Creative Commons Attribution License (http://creativecommons.org/licenses/by/3.0), which permits unrestricted use, distribution, and reproduction in any medium, provided the original work is properly cited.

\section{INTRODUCTION}

The gestational age is necessary in the management of pregnancy. It is usually estimated by ultrasound using parameters like femur length,

1. Ngozi R. Njeze,

Senior lecturer Department of Radiation Medicine,

2. Joseph O. Ogbochukwu,

Consultant Radiologist, Department of Radiology,

Federal Medical Center Nguru, Nigeria.

3. Josephat M. Chinawa

Associate Professor, Department of Pediatrics,

1,3: University of Nigeria Medical School,

Nsukka, Nigeria.

Correspondence:

Dr. Josephat M. Chinawa

Department of Paediatrics,

University of Nigeria, Enugu Campus,

Enugu, Nigeria.

E-mail: josephat.chinawa@unn.edu.ng

* Received for Publication:

November 7, 2019

* $1^{\text {st }}$ Revision Received:

* $2^{\text {nd }}$ Revision Received:

December 17, 2019

* Final Revision Accepted: bi-parietal diameter, abdominal circumference which have their limitation. It is imperative to seek other parameters to compliment them in predicting gestational age. ${ }^{1}$

The placenta is highly vascular and ensures adequate interaction between the mother and fetus. ${ }^{1-5}$ It is known that a healthy and normal placenta enhances fetal growth and is key in good perinatal result. ${ }^{2}$ Fetal growth is affected when placental function is not optimal. As a result, alteration in placental measurement is an indicator of abnormal fetal growth. ${ }^{2-9}$ Placental thickness is a key factor in perinatal outcome since it affects fetal development. At birth, placental thickness is about $3 \mathrm{~cm}$ while diameter is $15-25 \mathrm{~cm} .{ }^{10}$ Ultrasound done at $36 \mathrm{wks}$ measuring $18 \mathrm{~cm}$ in diameter and $2 \mathrm{~cm}$ at $36 \mathrm{wks}$ predicts a low birth weight neonate. ${ }^{11}$ Small sized placentas may result in intra-uterine growth restriction, chromosomal anomalies, severe maternal diabetes mellitus, preeclampsia, chronic intra uterine fetal infections, polyhydramnios. ${ }^{11}$ 
Large sized placentas (more than $4 \mathrm{~cm}$ thickness) at term are mostly due to diabetes mellitus, perinatal infections, \& hydrops fetalis. ${ }^{11,12}$ The assessment of PD and PT will enable the obstetrician achieve successful fetal outcome. Important clinical decisions like gestational age at which caesarian section, elective induction of labor depend on accurate timing of gestational age. ${ }^{12}$

There is a yearning gap created by other methods of assessment of gestational age. For instance, the use of last menstrual period (LMP), symphysiopubic fundal height (SFH) and Ballard Score (BS) at delivery, though often used they have limited role and lack of precision in estimating gestational age is gross. ${ }^{13} \mathrm{~A}$ well-coordinated ultrasound facility with its attendant skills will indeed be very essential in the study and management of gestational age in newborns. ${ }^{13}$

Jehan et al. ${ }^{14}$ in their study, compared the accuracy of the last menstrual period (LMP) and symphysis-fundal height (SFH) in the estimation of gestational age (GA), using ultrasound (US) scan as reference. They concluded that though SFH was a more accurate method of assessing gestational age than LMP, however, neither of the above tools were as accurate as the use of ultrasonography.

This study therefore aimed to find the correlation if any between placental diameter, thickness with gestational age and match placental health with placental diameter and thickness to gestational age and fetal outcome. It also hopes to guide obstetricians practicing in peripheral health centers to alert the neonatologists of those fetuses that may require extra care at birth.

\section{METHODS}

This is an observational cross-sectional study that examines by means of ultrasonography the correlation between placental diameter and thickness with gestational age in the University of Nigeria Teaching Hospital, Enugu, South East, Nigeria.

Study Area: The study was carried out among pregnant mothers who attend ante-natal clinic in UNTH Enugu, Nigeria.

This study comprised four hundred women with viable singleton pregnancy who met the inclusion criteria. They were consecutively recruited over one-year period.

This is an observational cross sectional study which spanned over one year period and involved 400 women with singleton pregnancies in their $3^{\text {rd }}$ trimester. They were scanned at They were scanned at 32 weeks' gestation, 36 weeks, and other times within the third trimester.

The gestational age is frequently over or under estimated as many women do not know their last menstrual period. Irregular menstruation is also going to add to this difficulty in accessing GA.

Measurement of placental diameter $\mathcal{E}$ thickness: A mobile ultrasound machine was used to acquire data; SONOSITE M-Turbo (made in USA). Curvilinear probe frequency of $3.5-5 \mathrm{mHz}$ with the participant lying in supine position on the examination couch, coupling gel was applied on the abdomen after exposing it. Placental thickness \& diameter were measured \& recorded in the data sheet.

It was done parallel to the length of the chorionic surface from upper to lower limit of the placenta. The placenta was measured by split screen method whereby the upper limit to midline was sited in one part of the screen; the other half of the screen was used to measure from the midline to the lower limit of the screen.

The placental thickness was measured perpendicularly at the level of the umbilical cord insertion from feto-placental surface to placenta-endometrial surface. Inclusion criteria were normal viable singleton pregnancy, at 28-41 weeks. Women who were not sure of their dates were not selected same as those with uterine masses or mothers with diabetes mellitus or sickle cell disease.

Data analysis: All data were analyzed using the Statistical Package for Social Sciences program (SPSS version 20 Chicago.) Chi-square was used to test significant association for qualitative variables while multivariate logistic regression was used to determine correlates. A p-value less than 0.05 was accepted as significant for each statistical test.

Ethical Considerations: Ethical clearance was dully obtained from the ethical and research committee of the University of Nigeria Enugu with IRB number of IRB00002323 and issue date of 17th May 2019. Participants were tutored about the study and their confidentiality assured.

\section{RESULTS}

A total of 400 healthy subjects were recruited in $3^{\text {rd }}$ trimester of pregnancy having fulfilled the inclusion criteria. Table-I shows demographic data of pregnant females aged between 20-44 years with a mean of 29.28 year \pm 3.52 . Modal age group was 30-34 years, 161(40.3\%) followed by $25-29$ years, age group which was $144(36.0 \%)$ 
Table-I: Demographic characteristics of the study population.

\begin{tabular}{lcc}
\hline Variables & Frequency & Percentages (\%) \\
\hline Age & & \\
$20-24$ & 50 & 12.5 \\
$25-29$ & 144 & 36 \\
$30-34$ & 161 & 40.3 \\
$35-39$ & 42 & 10.5 \\
$40-49$ & 3 & 0.7 \\
Total & 400 & 100 \\
Body mass index & & \\
Normal & 151 & 37.7 \\
Overweight & 165 & 41.3 \\
Obesity & 84 & 21.0 \\
Total & 400 & 100 \\
\hline
\end{tabular}

women. The least number was the $40-44$ age group which had 3 subject $(0.7 \%)$.

The number of subjects decreased with parity. Parity ranged from one to five. Multiparous women were 166 (41.5\%). Nulliparous women

Table-II: Obstetrics characteristics of the study population.

\begin{tabular}{lcc}
\hline Variables & $\begin{array}{c}\text { Frequency } \\
(n=400)\end{array}$ & $\begin{array}{c}\text { Percentages } \\
(\%)\end{array}$ \\
\hline Parity & 134 & 33.5 \\
0 (nulli-parous) & 98 & 24.5 \\
1 (primi-parous) & 80 & 20.0 \\
2 (multi-parous) & 55 & 13.8 \\
3 (multi-parous) & 31 & 7.7 \\
4 (multi-parous) & 2 & 0.5 \\
5 (grand-multiparous) & 400 & 100 \\
Total & & \\
Mode of delivery & \\
(spontaneous vaginal delivery & 344 & 86.0 \\
Caesarian section & 56 & 14.0 \\
Gestational age groups (weeks) & & \\
28-31 & 107 & 26.7 \\
$32-35$ & 147 & 36.7 \\
36-39 & 129 & 32.3 \\
$40-41$ & 17 & 1.3 \\
Gestation at delivery (weeks) & & \\
31-35 & 58 & 14.5 \\
$36-40$ & 274 & 68.5 \\
$40-41$ & 68 & 17.0 \\
Birth weight (kg) & & \\
$<2.5$ & 37 & 9.3 \\
$>$ 2.5 & 363 & 90.7 \\
Post-delivery gender & & \\
Male & 210 & 52.5 \\
Female & 190 & 47.5 \\
\hline & &
\end{tabular}

were 134 (35.5\%). 98 primi-parous women were $24.5 \%$ of the study population. There were two grand multiparous women $(0.5 \%)$.

PD \& PT in this study did not correlate with parity. There is a linear increase of gestational age and placental thickness and diameter. These increases heighten between $38^{\text {th }}$ week gestation and 40 weeks' gestation. $205.0 \pm 1.4,43.00 \pm 0.0$ to $215.0 \pm 1.4,46.00 \pm 2.8$ respectively.

\section{DISCUSSION}

Placental thickness is known to increase progressively with gestational age and at term the placenta is known to attain a weight of $500 \mathrm{~g} .{ }^{15,16}$ Its thickness tends to increase steadily with GA in a linear fashion. This progressive increase is by about one millimeter per week. The gestational age (in weeks) is same as placental thickness $\pm 10 \mathrm{~mm}$. Anteriorly located placenta is usually thinner than posterior placenta by about $0.7 \mathrm{~cm} .{ }^{17}$

Use of fetal parameters though helpful will need PT and PD to enhance accuracy of gestational age. Thurston $^{18}$ and Anna ${ }^{19}$ variously reported that placental thickness indeed parallels gestational age and that it has a very high correlation with GA. ${ }^{18}$ We also noted a strong correlation and linear increase of PT and PD with GA. Khanal ${ }^{20}$ and colleagues were hopeful that placental thickness would be used to estimate gestational age.

Mathai ${ }^{21}$ also reported that PT increases with gestational age. ${ }^{21}$ Placental thickness of $>40 \mathrm{~mm}$

Table-III: Mean placental \& foetal parameters by GA.

\begin{tabular}{lccc}
\hline $\begin{array}{l}\text { EGA } \\
(w k s)\end{array}$ & $\begin{array}{c}\text { No. of } \\
\text { subjects }(\mathrm{N})\end{array}$ & $\begin{array}{c}\text { Mean PD } \\
(\mathrm{mm}) \pm S D\end{array}$ & $\begin{array}{c}\text { Mean } P T \\
(\mathrm{~mm}) \pm S D\end{array}$ \\
\hline 28 & 25 & $167.8 \pm 25.8$ & $32.3 \pm 1.2$ \\
29 & 23 & $169.0 \pm 9.4$ & $32.75 \pm 2.6$ \\
30 & 24 & $180.0 \pm 3.0$ & $34.00 \pm 1.1$ \\
31 & 35 & $183.0 \pm 1.8$ & $35.00 \pm 1.3$ \\
32 & 50 & $184.7 \pm 2.3$ & $35.88 \pm 1.5$ \\
33 & 30 & $188.6 \pm 4.0$ & $37.00 \pm 3.3$ \\
34 & 34 & $192.0 \pm 15.3$ & $39.06 \pm 4.7$ \\
35 & 33 & $195.0 \pm 8.8$ & $40.50 \pm 3.4$ \\
36 & 45 & $194.2 \pm 7.8$ & $40.00 \pm 1.2$ \\
37 & 35 & $193.7 \pm 4.8$ & $39.00 \pm 0.7$ \\
38 & 31 & $205.0 \pm 1.4$ & $43.00 \pm 0.0$ \\
39 & 18 & $215.0 \pm 1.4$ & $46.00 \pm 2.8$ \\
40 & 12 & $208.0 \pm 2.8$ & $44.50 \pm 0.7$ \\
41 & 5 & $207.0 \pm 2.3$ & $43.50 \pm 0.4$ \\
\hline Total & 400 & $186.0 \pm 9.1$ & $36.5 \pm 2.9$ \\
\hline
\end{tabular}


at term is associated with gestational diabetes, intrauterine infection and hydrops fetalis. We obtained higher figures in our work similar to Karthikeyan. ${ }^{22}$ This supports the impression that placental thickness is most likely higher in negroes. Uterine contractions may alter placental thickness giving a false increase in thickness same as severe polyhydramnios and may decrease PT. Oligohydramnios may give a false increase in size. Kullman et al. ${ }^{23}$ showed that placental thickness less than $25 \mathrm{~mm}$ in $3^{\text {rd }}$ trimester is associated with intrauterine growth retardation. None of our subjects had either polyhydramnios or oligohydroaminios. $\mathrm{Mital}^{24}$ in India and Kadam ${ }^{1}$ also in India concluded that placental thickness is important in estimating gestational age especially when patients are not sure of their dates.

We noted from our study that parity does not correlate with PD and PT. There is an increase of placental thickness especially at the second and third trimester. These findings are also in keeping with ours. However, it is expedient to note that increased placental thickness is not diagnostic of any specific disorder but may contribute to the management of a fetus at risk. In addition, increases in placental thickness during second trimester is due to over-inflation of the intervillous space by maternal blood rather than by adaptive formation of functional placental tissue. Higgins ${ }^{25}$ and colleagues went further to correlate antenatal placental assessment with reduced fetal movement. ${ }^{25}$ Noor $^{26}$ and colleagues identified placental thickness as a promising tool for estimating fetal weight.

Kinare $^{27}$ in India and Fang ${ }^{28}$ found there was significant relationship between mid pregnancy placental volume and birth weight. ${ }^{27}$ Campbell et al. $^{29}$ are of the opinion that effective placental volume is a new useful parameter for identifying small for gestational age babies.

Isakov $^{4}$ and co -workers also did their work on placental volume and observed there was a weak correlation between estimated placental volume and birth weight. ${ }^{4}$ We observed that only few authors like Habib ${ }^{11}$ carried out studies on placental diameter. She found that using PD and PT could be a good prognostic assessment for identifying retarded fetal growth.

Limitation of the study: This is a single center study. A cohort or a wider community study would be worthwhile.

\section{CONCLUSION}

Placental thickness and Placental diameter can be used to predict gestational age. It is therefore advised to use PT \& PD in ultrasound obstetric assessment especially when last menstrual period is not clear.

Recommendation: We recommend more studies to lay emphasis on placental diameter as most researchers concentrated more on placental thickness.

Acknowledgements: We acknowledge the nurses who helped in retrieving the folders.

Disclosure: None.

Funding: None

\section{REFERENCES}

1. Kadam D, Patil S, Jain M. Placental Thickness: An Important Parameter in Determining Gestational Age and Fetal Growth During ANC Scan. Int J Reproduct Contracept Obstet Gynecol. 2018;7(11):4619-4622.

2. Yoshizawa RS. 2013. Review: Public perspectives on the utilization of human placentas in scientific research and medicine. Placenta. 2013;34:9-13. doi: 10.1016/j. placenta.2012.10.014

3. Wallingford MC, Benson C, Chavkin NW, Chin MT, Frasch MG. Placental Vascular Calcification and Health: It is Time to Determine How Much of Maternal and Offspring Health Is Written in Stone. Front Physiology. 2018;9:1044. doi: 10.3389/ fphys.2018.01044

4. Isakov MM, Emerson JW, Campbell KH, Galerneau F, Anders AM, Lee YK, et al. Estimated Placental Volume and Gestational Age. Am J Perinatol. 2018;(35)8:748-757. doi: 10.1055/s-0037-1615285

5. Baghel P, Bahel V, Paramhans R, Sachdev P, Onkar S. Correlation of Placental Thickness Estimated by Ultrasonography with Gestational Age and Fetal Outcome. Ind J Neonatal Med Res. 2015;3(3):19-24. doi: IJNMR/2014/13676.2057

6. Karowicz-Bilinska A, Kedziora-Kornatowska K, Bartosz G. Indices of oxidative stress in pregnancy with fetal growth restriction. Inform Health Care. 2007;41:870-873. doi: $10.1080 / 10715760701291647$

7. Otiv S, Coyaji K. Fetal growth restriction. In: Krishna U, Shah D, Salvi V, Sheriar N, Damania K, editors. Pregnancy at risk. 5th ed. New Delhi: Jaypee Brothers Medical Publishers (P) Ltd. 2010. doi: 10.1007/s13224011-0092-x

8. Zimmermann P, Eirio V, Koskinen J. Doppler assessment of the uterine and uteroplacental circulation in the second trimester in pregnancies at high risk for pre-eclampsia and or intrauterine growth retardation: Comparison between different Doppler parameters. Ultrasound Obstet Gynecol. 2001;18:441-449. doi: 10.1046/j.14690705.1997.09050330.x

9. Damodaram M, Story L, Eixarch E. Placental MRI in fetal growth restriction. Placenta. 2010;31(6):491-498. doi: 10.1016/j.placenta.2010.03.001 
10. Tongprasert F, Srisupundit K, Luewan S, Tongsong T. Second trimester maternal serum alpha-fetoprotein (MSAFP) as predictor of fetal hemoglobin Bart's disease. Prenat Diagn. 2014;34(13):1277-1282. doi: 10.1002/ pd. 4465

11. Habib FA. Prediction of low birth weight infants from ultrasound measurement of placental diameter and thickness. Ann South Saudi Med. 2002;22(5-6):312-314. doi: 10.5144/0256-4947.2002.312

12. Foidart JM, Seak-San S, Emonta P, Schaaps JP. Vascular placental pathology in high-risk groups: Definition and synopsis. Ann Med Int (Paris). 2003;154 (5-6):332-339.

13. Holger U, Kamala T, Benedikt L, Halidou T, Maminata $\mathrm{T}$, Innocent $\mathrm{V}$ et al. The Assessment of Gestational Age: A Comparison of Different Methods from a Malaria Pregnancy Cohort in sub-Saharan Africa. BMC Pregnancy Childbirth. 2019;19:12. doi: 10.1186/ s12884-018-2128

14. Jehan I, Zaidi S, Rizvi S, Mobeen N, McClure EM, Munoz B Et al. Dating gestational age by last menstrual period, symphysis-fundal height, and ultrasound in urban Pakistan. Int J Gynaecol Obstet. 2010;110(3):231-234. doi: 10.1016/j.ijgo.2010.03.030

15. Azpurua H, Funai EF, Coraluzzi LM, Sasson IE, Kliman M, Kliman HJ. Determination of Placental Weight Using Two -Dimensional Sonography and Volumetric Mathematic Modeling. Am J Perinatol. 2010;27(2):151155. doi: 10.1055/s-0029-1234034

16. Review of MEDICAL EMBRYOLOGY Book by BEN PANSKY ... Obtainable from: https://discovery. lifemapsc.com/library/review-of-medical-embryology. Assessed on $11 / 05 / 2020$

17. Ganjoo S, Devgan S, Ghanshyan D. Second Trimester Placental Thickness: its Correlation with Gestational Age, Femur Length and Biparietal Diameter. Int J Reproduct Contracept Obstet Gynecol. 2018;7(9):3568-3571. doi: 10.18203/2320-1770.ijrcog20183461

18. Thurston M, Weerakoddy Y. Placental Thickness. Available from: https://radiopaedia.org/articles/ placental thickness. Accessed on 11/05/2020

19. Anna JL, Michael B, Richard JH. Placental Thickness in the Second Trimester. J Ultrasound Med. 2012;31(2):213218. doi: 10.7863 /jum.2012.31.2.213

20 Khanal UP, Paudel S, Lohani B. Ultrasonographic Measurement of Placental Thickness During Pregnancy as a Parameter For Estimating Gestational Age of the Foetus. Nepal J Radiol. 2017;7(10):13-18. doi: 10.3126/ njr.v7i1-2.19349

21. Mathai B, Singla SC, Nittala PP, Chakravarti RJ, Toppo JN. Placental Thickness: Its Correlation with Ultrasoographic Gestational Age in Normal and Intrauterine Growth - Retarded Pregnancies in the Late Second and Third Trimester. J Obstet Gynecol India. 2013;63(4):230-233. doi: 10.1007/s13224-012-0316-8
22. Karthikeyan $\mathrm{T}$, Subramaniam RK, Johnson W, Prabhu K. Placental thickness \& its correlation to gestational age \& foetal growth parameters - a cross sectional ultrasonographic study. J Clin Diagnos Res. 2012;6(10):1732-1735. doi: 10.7860/JCDR/2012/4867.2652

23. Kullmann RS, Warsof S. Ultrasound of the placenta. Clin Afr. J Obstet Gynecol. 1996;39:34. doi: IJNMR/2014/13676.2057

24. Mital P, Hooja N, Mehndiratta K. Placental Thickness: A Sonographic Parameter for Estimating Gestational Age of the Fetus. IJRI. 2002;12(4):553-554.

25. Higgins LE, Myers JE, Sibley CP, Heazell AEP, Johnstone ED. Third Trimester Placental Volume and Biometry Measurement: A Method - Development Study. Placenta. 2016;42:51-58. doi: 10.1016/j.placenta.2016.04.010

26. Noor N, Jain A, Parveen S, Ali SM. Ultrasonographic measurement of placental thickness and its correlation with estimated fetal weight. Int J Reproduct Contracept Obstet Gynecol. 2018;7:287-290. doi: 10.18203/2320-1770. ijrcog20175863

27. Kinare AS, Natekar AS, Chinchwadkar MC, Yajnik CS, Coyaj KJ, Fall CHD, et al. Low mid pregnancy placental volume in rural Indian women: A cause for low birth weight? Am J Obstet Gynecol. 2000;182(2):443-448. doi: 10.1016/s0002-9378(00)70237-7

28. Fang SW, Ou CY, Tsai CC, Fu HC, Cheng HH, Cheng BH et al. Second-trimester placental volume and vascular indices in the prediction of small-for-gestationalage neonates. Fetal Diagn Ther. 2015;37(2):123-128. doi: $10.1159 / 000365148$

29. Campbell C, Galerneau F, Kilman H, Bukowski RK. Estimated placental volume - A novel predictor of small for gestational age birth weight. Am J Obstet Gynecol. 2016;214(1):303. doi: 10.1055/s-0037-1615285

\section{Authors' Contribution:}

NRN \& JMC, contributed to the conception, writing and proof reading of this manuscript.

JOO: Contributed in data and statistical analysis of this work, while.

NRN \& JOO: Contributed in proofreading the manuscript. All authors read and approved the final manuscript.

JOO \& NRN: Are guarantors of the paper.

All authors contributed to the conception and writing of the manuscript. 